of hand-tool used in the construction and rail-maintenance industries in the North American (NA) and EU market.

Methods A product information search of hand-operated tools was performed utilising online resources in the specific EU and NA market. Vibration data from independent or governmental sources was compared with manufacturer information.

Results A comparison of leading EU and NA manufacturers' $(n=18)$ web sites, sales catalogues, product manuals, and expert interviews showed vibration emissions should by listed i.e. breakers, grinders, tamping guns, spiking guns, rail drills, grinders, spike pullers/drivers, tampers and saws. Only one international manufacturer listed in the EU and NA markets vibration emission information following the ISO standard. The majority of manufacturers in both markets $(n=17)$ did not list any or only partial information about the vibration levels $\left(a_{h},\right)$ uncertainty factor $(\mathrm{K})$, and the utilised measurement standard. In the EU one third of the listings showed the required emission information and the measurement standard was mentioned in $40 \%$. In the NA market $20 \%$ of the hand-tools showed any vibration information and more than half had no emission listing at all. Variation of the measurement standards utilised by the manufacturer limit a comparison of tools from different manufacturer.

Conclusion This study showed that compared to the EU only very limited information and specific data is provided by international manufacturer in the NA market about HAV emissions of hand tools used in construction and rail industry. A user is often left required to make decisions with insufficient or conflicting information.

- 'DIRECTIVE 2006/42/EC OF THE EUROPEAN PARLIAMENT AND OF THE COUNCIL of 17 May 2006 on machinery, and amending Directive 95/16/EC (recast).' Official Journal of the European Union: EC of the European Parliament and of the Council, 2006.

- ISO 20643: Mechanical vibration-Hand-held and handguided machinery-Principles for evaluation of vibration emission. CH-Geneva ISO (International Organisation for Standardisation), 2005.

\section{HAND-ARM VIBRATION AND THE RISK OF NEUROLOGICAL DISEASES - A SYSTEMATIC REVIEW AND META-ANALYSIS}

Tohr Nilsson*, Jens Wahlström, Lage Burström. Occupational and Environmental Medicine, Department of Public Health and Clinical Medicine, Umeå University, Umeå, Sweden

\subsection{6/oemed-2018-ICOHabstracts. 1454}

Introduction The current risk prediction modelling (ISO-5349) for 'Raynaud's phenomenon' is based on a few studies published 70 to 40 years ago. There are no corresponding risk prediction models for neurosensory injury or carpal tunnel syndrome, nor any systematic reviews comprising a statistical synthesis (meta-analysis) of the evidence.

Methods This systematic review covers the scientific literature up to January 2016. The databases used for the literature search were PubMed and Science Direct. We found a total of 4335 abstracts, which were read and whose validity was assessed according to pre-established criteria. 294 articles were examined in their entirety to determine whether each article met the inclusion criteria. The possible risk of bias was assessed for each article. 52 articles finally met the pre-established criteria for inclusion in the systematic review. For the outcome neurosensory injury, 33 articles were included and for Carpal tunnel syndrome 7.

Result The results show that workers who are exposed to HAV have an increased risk of neurological diseases compared to non-vibration exposed groups. The crude estimate of the risk increase is approximately $4-5$ fold. The estimated effect size (odds ratio) of neurosensory injury is 7.4 , when including only the studies judged to have a low risk of bias and the equivalent of carpal tunnel syndrome is 2.9.

Discussion At equal exposures, neurosensory injury occurs with a 3-time factor shorter latency than Raynaud's phenomenon. Which is why preventive measures should address this vibration health hazard with greater attention.

\section{REFERENCE}

1. Nilsson T, Wahlström J, Burström L. Hand-arm vibration and the risk of vascular and neurological diseases: A systematic review and meta-analysis. PloS One. 2017;12(7):e0180795.

\section{NOISE LEVELS IN A ENQUIRY OFFICE}

${ }^{1}$ Sue Reed, ${ }^{1}$ Martyn Cross, ${ }^{1}$ Jacques Oosthuizen, ${ }^{2}$ Maggie Davidson. ${ }^{1}$ Edith Cowan University; ${ }^{2}$ Western Sydney University

\subsection{6/oemed-2018-ICOHabstracts. 1455}

Introduction The use of open plan offices in face-to face contact centres and phone contacts centres has become a trend over the 20 years. This paper will present the outcomes of noise monitoring in two contact centres which deal with enquires from students in a university.

Methods The noise exposure of a minimum of 10 participants were measured in each location on a number of days, as specified in AS/NZS 1269.1:2005. This repeat monitoring was undertaken to ascertain if the exposures differed significantly between days and different office environments. In addition the ambient noise levels were measured to determine if the environment met the design requirements for acoustics as specified in AS/NZS 2107:2016 Acoustics-Recommended design sound levels and reverberation times for building interiors.

Results The results showed that none of the personnel exposures exceeded the Occupational Nosie Exposure Standard of $\mathrm{L}_{\text {eq }}$ of $85 \mathrm{dBA}$ for 8 hours, as expected. The highest personal exposure in Location 1 was $76.5 \mathrm{dBA}$ and in Location 2 was $78.2 \mathrm{dBA}$, but this only occurred on one day each. The minimum ambient levels were within the specification of AS/NZS 2107:2016 of 40 to $45 \mathrm{dBA}$.

Discussion The levels of noise measured in the enquiry office were well below the current Australian standard for occupational noise exposure $\left(\mathrm{L}_{\mathrm{eq}}\right.$ of $\left.85 \mathrm{dBA}\right)$, therefore they meet current legislative requirements, and did not constitute a noise induced hearing loss issue. However, it is considered that such noise levels may contribute to speech intelligibility and communication issues, potentially reducing productivity, and possibly instituting fatigue, due to the reverberant nature of the environment. 